hij daarmee eventueel tekortschiet jegens zijn wederpartij' (Stolz 2015, p. 572-574). Ook toepassing van dit criterium noopt mijns inziens tot de conclusie dat het door de zorgaanbieder voldoen aan de Declaratieregeling niet als vereiste voor het ontstaan van diens vorderingen op zorgverzekeraars is aan te merken. De zorgverzekeraars konden zich immers niet eenzijdig van hun betalingsverplichtingen ontdoen. Zoals ook de rechtbank overweegt, geeft de Declaratieregeling hooguit voorwaarden voor de opeisbaarheid van vorderingen tot betaling van een geldsom voor verleende zorg.

15. Het voorgaande geldt in feite ook voor de vorderingen met oorsprong in de behandelingsverhouding. Ook die ontstaan mijns inziens telkens na het verrichten van een in de tariefbeschikking omschreven deelprestatie, behoudens andersluidende afspraak en al zijn ze pas later opeisbaar. Dat volgt mijns inziens uit de aard van de overeenkomst en hoeft niet expliciet door partijen overeengekomen te worden, zoals het hof wel lijkt te eisen in r.o. 3.9. Het hof vergelijkt de behandelingsovereenkomst met de overeenkomst tot aanneming van werk, waarbij in beginsel pas loon is verschuldigd na totstandkoming van het werk. Waar echter de aanneming van werk een 'doelopdracht' is met als eindresultaat een tot stand gebracht werk, heeft de geneeskundige behandeling kenmerken van wat Tjong Tjin Tai een 'voortdurende opdracht' noemt. Vooropstaat het bieden van goede medische zorg en niet het bereiken van een resultaat als 'genezing', al kan dat voor onderdelen van de zorgverlening anders zijn. Zie Asser/Tjong Tjin Tai 7-IV 2014/129 en 406; Schuiling 2016, p. 150; Kamerstukken II, 1989/90, 21561, 3, p. 42. Het doel wordt evenmin gevormd door het administratief afronden van een DBC.

\section{Slot}

16. Volgen wij het oordeel van het hof dan ontstaan vorderingen van zorgverzekeraars op zorgaanbieders waarop de Declaratieregeling van toepassing is pas als de betreffende DBC's zijn gesloten en gevalideerd, indien en voor zover zorgverzekeraar en zorgaanbieder niet anders overeengekomen zijn. Evenals de rechtbank ben ik echter van mening dat de Declaratieregeling niet meer dan gronden voor opeisbaarheid van de vorderingen bevat. De uitleg die het hof geeft aan de Declaratieregeling en de rechtsverhouding tussen zorgverzekeraar en zorgaanbieder past niet bij het doel en de strekking van de Declaratieregeling, de wederkerigheidsverhouding tussen zorgverzekeraar en zorgaanbieder en de jurisprudentie en theorie over het onderscheid tussen bestaande en toekomstige vorderingen. Daarnaast is heroverweging van het oordeel van het hof in het belang van de financiering van de curatieve GGZ in Nederland.

17. Tegen het arrest van het hof is cassatieberoep ingesteld.

Mr. H.A. ten Oever, promovenda aan het Instituut voor Privaatrecht, Universiteit Leiden. Haar promotieonderzoek ziet op zorginkoopovereenkomsten in het kader van de Zorgverzekeringswet.

\title{
2016/254 Centraal Tuchtcollege, 7 april 2016 (m.nt. van prof. mr. J.C.J. Dute)
}

\author{
Centraal Tuchtcollege voor de Gezondheidszorg, 7 april \\ 2016 (mrs. Altena, Smeeïng-van Hees en Veldhuisen, prof. \\ dr. Klautz en dr. De Rotte), zaaknr. C2015.139, A tegen C \\ (cardioloog), ECLI:NL:TGZCTG:2016:156
}

\section{Verloop van de procedure}

A. - hierna klager - heeft op 25 augustus 2014 bij het Regionaal Tuchtcollege te Den Haag tegen C. hierna de cardioloog - een klacht ingediend. Bij 
beslissing van 9 december 2014, onder nummer 2014-229 heeft dat College klager in de klacht nietontvankelijk verklaard.

Klager is van die beslissing tijdig in hoger beroep gekomen.

De cardioloog heeft een verweerschrift in hoger beroep ingediend.

De zaak is in hoger beroep tegelijkertijd maar niet gevoegd met de zaak C2015.138 (A./D., cardioloog) behandeld ter openbare terechtzitting van het Centraal Tuchtcollege van 16 februari 2016, waar zijn verschenen klager en de cardioloog, bijgestaan door $\mathrm{mr}$. A. Jagt voornoemd. Partijen hebben pleitnotities overgelegd.

\section{Beslissing in eerste aanleg}

Het Regionaal Tuchtcollege heeft aan zijn beslissing de volgende overwegingen ten grondslag gelegd.

"2. De klacht

Klager is als cardioloog werkzaam geweest in het E. Ziekenhuis te B. (hierna: het ziekenhuis). Verweerder is werkzaam als cardioloog in het ziekenhuis.

Op 21 oktober 2010 is in het ziekenhuis de heer F. (hierna: patiënt) overleden. Klager verwijt verweerder dat hij patiënt geen (gerichte) behandeling heeft gegeven voor zijn hartinfarct, waardoor patiënt is komen te overlijden.

3. De beoordeling

3.1. Op grond van het bepaalde in artikel 65, lid 1 onder a van de Wet op de beroepen in de individuele gezondheidszorg (de Wet BIG) wordt een tuchtzaak aanhangig gemaakt door een schriftelijke klacht van - voor zover thans aan de ordeeen rechtstreeks belanghebbende. Onder dit begrip vallen in ieder geval de patiënt zelf en de nabestaanden van de overleden patiënt. Een redelijke wetstoepassing brengt voorts mee dat de naaste betrekkingen ook als rechtstreeks belanghebbende kunnen worden aangemerkt wanneer de patiënt met de indiening van de klacht instemt. Klager is een (voormalige) collega van verweerder. Voorop staat dat een collega werkzaam in de gezondheidszorg, behoudens bijzondere omstandigheden, in het algemeen geen rechtstreeks belang in voormelde zin heeft bij het indienen van een klacht. Om aangemerkt te kunnen worden als klachtgerechtigde dient er aan de zijde van klager sprake te zijn van een belang dat kan worden geplaatst in het kader van de individuele gezond- heidszorg én waaraan klager een bijzonder eigen belang ontleent

3.2. Het College begrijpt uit stelling weergegeven onder 2. dat klager klaagt over de behandeling door verweerder van (de overleden) patiënt. De nabestaande van patiënt, zijn dochter, heeft laten weten geen machtiging voor het indienen van een tuchtklacht te verstrekken. Nu klager bovendien geen nabestaande of naaste betrekking van patiënt is, is hij reeds hierom niet als zodanig gerechtigd een tuchtklacht in te dienen over een gedraging van verweerder in het kader van zijn behandeling van patiënt. Van enig belang dat kan worden geplaatst in het kader van de individuele gezondheidszorg en waaraan klager een bijzonder eigen belang ontleent, is niet gebleken. Klager zal dan ook niet-ontvankelijk worden verklaard omdat hij niet als rechtstreeks belanghebbende kan worden aangemerkt

3.3. Overigens wekt het bij het College bevreemding dat klager de medische gegevens van een (overleden) patiënt zonder toestemming van de patiënt en/of een nabestaande/naaste betrekking van patiënt, anders dan als behandelaar, gebruikt en inbrengt in de onderhavige tuchtprocedure. Dit roept de vraag op of klager hiermee zijn beroepsgeheim schendt."

\section{Beoordeling van de ontvankelijkheid van het hoger beroep}

3.1. De cardioloog heeft in hoger beroep aangevoerd dat klager niet in zijn beroep kan worden ontvangen, omdat - kort gezegd - klager geen gronden van beroep heeft geformuleerd.

3.2. Klager heeft in zijn beroepschrift d.d. 13 maart 2015 en zijn aanvullend beroepschrift d.d. 2 juni 2015 aangegeven dat het Regionaal Tuchtcollege de niet-ontvankelijkheid onjuist heeft beoordeeld. In dat verband heeft klager (onder meer) opgemerkt dat het ontbreken van een familiaire verbintenis en het ontbreken van een machtiging van klager of van diens nabestaande geen belemmering mag zijn om in het kader van de individuele gezondheidszorg voor het patiëntbelang van (de overleden) patiënt $\mathrm{F}$. te mogen opkomen in het bestek van de tuchtrechtelijke procedure. Klager heeft - zakelijk weergegeven - aangevoerd dat hij een eigen belang heeft bij het opkomen voor het belang van patiënt door 
middel van een klacht hetgeen is geworteld in het feit dat de individuele gezondheidszorg een algemeen goed is waartoe mede de belangen van klager gerekend dienen te worden. Aldus heeft klager gronden voor beroep aangevoerd. Klager wordt daarom in zijn beroep ontvangen.

\section{Beoordeling van de ontvankelijkheid van klager in de oorspronkelijke klacht}

4.1. Het Centraal Tuchtcollege zal voordat de zaak inhoudelijk behandeld kan worden, eerst moeten beoordelen of klager klachtgerechtigd is op grond van artikel 65 lid 1 onder a Wet BIG.

4.2. Klager is de (voormalige) collega van de cardioloog en wenst een klacht in te dienen over de behandeling van de (overleden) patiënt F. door de cardioloog. Klager is geen nabestaande of naaste betrekking van de patiënt.

4.3. Het Centraal Tuchtcollege heeft voorts vastgesteld dat klager niet is gemachtigd door een nabestaande of rechtstreekse betrekking van de patiënt. Mevrouw G., dochter en enig kind van de patiënt, heeft zelf geen klacht ingediend. Zij heeft aan klager te kennen gegeven dat zij klager niet zal machtigen tot het aanhangig maken van een tuchtrechtelijke procedure. Ook overigens is het Centraal Tuchtcollege niet gebleken dat klager is gemachtigd om namens de patiënt een tuchtrechtelijke procedure aanhangig te maken. Klager heeft zijn stelling dat hij de patiënt had beloofd te onderzoeken of hij door de cardioloog goed was behandeld en dat de patiënt hem mondeling had gemachtigd om zo nodig een klacht in te dienen, tegenover de gemotiveerde betwisting daarvan door de cardioloog, niet aannemelijk gemaakt.

4.4. Daarnaast heeft klager geen feiten of omstandigheden gesteld, en zijn deze zijn ook anderszins niet gebleken, op grond waarvan klager als (voormalig) collega van de cardioloog en medebehandelaar van de patiënt door het beklaagde handelen van de cardioloog in zijn professionele autonomie of anderszins zodanig is geschaad dat hij daardoor een concreet aan de individuele gezondheidszorg gerelateerd eigen belang heeft op grond waarvan hij als (voormalig) collega rechtstreeks belanghebbende is uit hoofde van artikel 65 lid 1 onder a Wet BIG.

4.5. Anders dan klager heeft aangevoerd geldt het door hem gestelde belang bij het indienen van een klacht op grond van het feit dat de individuele gezondheidszorg een algemeen goed is waartoe mede de belangen van klager gerekend dienen te worden, niet als een eigen belang op grond waarvan klager als rechtstreeks belanghebbende kan worden aangemerkt. Klager onderscheidt zich hierin immers niet van anderen.

4.6. Voor zover er in eerste aanleg sprake zou zijn geweest van een verzuim in de door het Regionaal Tuchtcollege gevolgde procedure door het onjuist informeren van klager over zijn klachtgerechtigdheid, zoals klager in beroep heeft aangevoerd, is dit hersteld door de behandeling van de zaak in hoger beroep. Het Centraal Tuchtcollege heeft de zaak ter zitting mondeling behandeld, waar klager zijn standpunten ten aanzien van zijn klachtgerechtigdheid aan het Centraal Tuchtcollege ter beoordeling heeft kunnen voorleggen.

4.7. Uit al het voorgaande volgt dat het Regionaal Tuchtcollege klager op goede gronden in de klacht niet-ontvankelijk heeft verklaard.

Dit betekent dat het beroep wordt verworpen.

\section{Beslissing}

Het Centraal Tuchtcollege voor de Gezondheidszorg:

verwerpt het beroep.

bepaalt dat deze beslissing op de voet van artikel 71 Wet BIG zal worden bekendgemaakt in de Nederlandse Staatscourant, en zal worden aangeboden aan het Tijdschrift voor Gezondheidsrecht, Gezondheidszorgjurisprudentie en Medisch Contact met het verzoek tot plaatsing. 


\section{Noot}

1. In bovenstaande uitspraak dient een cardioloog een klacht in tegen een ex-collega over de behandeling van een inmiddels overleden patiënt. Volgens het CTG kan hij echter niet in zijn klacht worden ontvangen, omdat hij geen 'rechtstreeks belanghebbende' is. Hij is geen nabestaande of rechtstreekse betrekking van de patiënt en is ook niet door een van hen gemachtigd. De dochter, en enig kind van de patiënt, heeft klager verder te kennen gegeven dat zij hem niet zal machtigen (r.o. 4.3). Klager is evenmin 'door het beklaagde handelen van de cardioloog in zijn professionele autonomie of anderszins zodanig geschaad dat hij daardoor een concreet aan de individuele gezondheidszorg gerelateerd eigen belang heeft op grond waarvan hij als (voormalig) collega rechtstreeks belanghebbende is uit hoofde van artikel 65 lid 1 onder a Wet BIG' (r.o. 4.4).

2. De uitspraak is ter publicatie aangeboden. Dat betekent meestal dat er iets nieuws of interessants onder de zon is. Dat is hier eigenlijk niet het geval. De boven geciteerde overweging kennen we al van CTG 30 september 2008, nr. 2007/211, Medisch Contact 2009, p. 118-120. Wel trekt r.o. 4.5 de aandacht. Daarin staat: 'Anders dan klager heeft aangevoerd geldt het door hem gestelde belang bij het indienen van een klacht op grond van het feit dat de individuele gezondheidszorg een algemeen goed is waartoe mede de belangen van klager gerekend dienen te worden, niet als een eigen belang op grond waarvan klager als rechtstreeks belanghebbende kan worden aangemerkt. Klager onderscheidt zich hierin immers niet van anderen.' Dat laatste gaat in zijn algemeenheid overigens te ver. Dat de arts ten aanzien van de individuele gezondheidszorg een bijzondere verantwoordelijkheid heeft, en daarmee een belang heeft dat zich onderscheidt van dat van niet-artsen, kan toch moeilijk worden ontkend. Zo wordt een arts geacht (een gegrond vermoeden van) disfunctioneren van een collega bespreekbaar te maken, bijvoorbeeld door de betreffende collega hierop aan te spreken, de raad van bestuur van het ziekenhuis hiervan op de hoogte te stellen of een melding te maken bij de IGZ (vgl. CTG 29 april 2004, Medisch Contact 2004, 22, p. 919-922). Patiënten hebben die plicht, die voortvloeit uit het belang van het goed functioneren van de zorg, niet. Maar dat betekent natuurlijk nog niet dat dat de arts in een dergelijke situatie een voldoende eigen belang heeft ter zake van het indienen van een tuchtklacht.

3. Bovenstaande uitspraak is niet helemaal consistent met de bekende CTG-uitspraak inzake de plastisch chirurg die zich beklaagde over een basisarts die zich 'cosmetisch chirurg' noemde. De plastisch chirurg werd in zijn klacht ontvangen nu 'hij als collega arts in de arts/patiëntrelatie met zijn patiënten schade ondervindt door het handelen van de arts'. Die schade bestond er uit dat 'door dat handelen het vertrouwen van de patiënt in de plastische chirurgie wordt ondermijnd'. Mijns inziens kan dit evenmin worden beschouwd als een voldoende eigen belang. Een belangrijk verschil is natuurlijk wel dat deze zaak niet ging over de behandeling van een concrete patiënt, zoals in bovenstaande casus. Vergelijk ook RTG Amsterdam 23 januari 2007, TvGR 2007, p. 565-570, waarin klager met gefingeerde gegevens een bestelling had gedaan bij een internetdokter om zijn vermoeden bevestigd te krijgen dat de aangeklaagde arts antibiotica verstrekte zonder de patiënt te zien en zonder enig laboratoriumonderzoek. Het college overwoog: 'Onweersproken is dat klager arts en seksuoloog is en er dus in zoverre reeds belang bij heeft dat op zijn terrein adequate gezondheidszorg volgens de geldende regels wordt verleend, meer in het bijzonder dat aan SOA gerelateerde klachten juist worden behandeld.' Ook dit kan toch moeilijk als een voldoende eigen belang worden beschouwd. Maar ook hier was geen andere patiënt bij betrokken. Ik kan mij niet aan de indruk onttrekken dat de overweging inzake het onvoldoende eigen belang in bovenstaande uitspraak zelfstandige betekenis mist. Het CTG wil voorkomen dat anderen dan de nabestaanden van de patiënt (zonder machtiging) toegang tot de tuchtrechter krijgen. Dat is hier ongetwijfeld beslissend geweest. Dat het CTG in dit soort gevallen de deur dichthoudt, is overigens goed te begrijpen. Een te ruime invulling van het 
belanghebbende-begrip kan onverkwikkelijke gevolgen hebben, waarbij ik met name denk aan het inbrengen in de procedure van de medische gegevens van de patiënt.

4. Vanuit het bestuursrecht kennen we voor het aannemen van 'rechtstreeks belang' de volgende criteria: het moet een eigen belang zijn, niet het belang van een ander (dan is een machtiging nodig); het belang moet objectief bepaalbaar zijn, dat wil zeggen niet slechts bestaan in iemands persoonlijke belevingswereld; het belang moet actueel zijn, het moet niet gaan om iets wat zich mogelijk in de toekomst kan voordoen; het belang moet verder persoonlijk zijn, dat wil zeggen de betrokkene moet zich onderscheiden van willekeurige anderen; en, ten slotte, het belang moet niet afhankelijk zijn van een ander of van nadere besluitvorming (Van Wijk/Konijnenbelt \& Van Male, Hoofdstukken van bestuursrecht, Alphen aan de Rijn: Wolters Kluwer 2014, p. 67 e.v.). Dit stramien is naar mijn oordeel ook bruikbaar in het tuchtrecht. In bovenstaande uitspraak verwijst het CTG naar het eerste en het vierde criterium. Dit zijn ook de twee criteria die in de tuchtrechtspraak het vaakst worden gehanteerd.

5. De jurisprudentie over de vraag in hoeverre een beroepsbeoefenaar een collega tuchtrechtelijk kan aanspreken, is nogal casuïstisch. Zie voor een beknopt overzicht L.E. Kalkman-Bogerd, in: D.P.
Engberts et al., Tekst $\mathcal{E}$ Commentaar Gezondheidsrecht, Deventer: Wolters Kluwer 2015, p. 184-185.

6. Een arts kan een klacht tegen een collega ook indienen bij de verenigingstuchtrechter van de KNMG. Het bereik van de verenigingstuchtrechter beperkt zich niet tot 'handelingen op het gebied van de individuele gezondheidszorg'. Voor hem is het vertrekpunt het vertrouwen in en de belangen van de geneeskundige stand. Cijfers ontbreken, maar meer dan enkele malen per jaar schijnt langs deze weg niet te worden geklaagd. Slechts af en toe wordt een uitspraak gepubliceerd. Al met al blijft deze vorm van rechtspraak een ietwat schimmig geheel. Veel klachten gaan blijkbaar over oncollegiaal gedrag (D.Y.A. van Meersbergen, 'KNMG: Collega's in de arena', Medisch Contact 2008, 4, p. 175). Ook veel andere beroepsgroepen, al dan niet onderworpen aan het wettelijke tuchtrecht, kennen verenigingstuchtrecht. Een door de verenigingstuchtrechter opgelegde maatregel staat niet in de weg aan een veroordeling door de wettelijke tuchtrechter. De nebis-in-idemregel van art. 51 Wet BIG is alleen van toepassing bij een onherroepelijke beslissing van het Regionale dan wel het Centrale Tuchtcollege (CTG 29 april 2004, Stcrt. 2004, 88).

Prof. mr. J.C.J. Dute, hoogleraar gezondheidsrecht te Nijmegen en lid van de redactie van dit tijdschrift

\section{6/303 Afdeling bestuursrechtspraak, 1 juni 2016 (m.nt. van mr. M.E.F. Bots)}

\begin{abstract}
Afdeling bestuursrechtspraak Raad van State, 1 juni 2016 (mrs. Van Altena, Van Ettekoven en Hagen), zaaknr. 201506364/1/A2, [appellante], wonend te Tuitjenhorn, gemeente Schagen, in haar hoedanigheid van erfgenaam van [overledene] en eigenaresse van Huisartsenpraktijk Tuitjenhorn tegen de inspecteur voor de volksgezondheid, ECLI:NL:RVS:2016:1502
\end{abstract}

\section{Procesverloop}

Bij besluit van 2 oktober 2013 heeft de inspecteur aan de huisartsenpraktijk het bevel gegeven dat de in de huisartsenpraktijk werkzame huisarts [overledene] met ingang van 2 oktober 2013 om 14.00 uur voor de duur van zeven dagen geen zorg meer in de huisartsenpraktijk verleent en niet anderszins 